This article has been published as

Moreno, M.; Sánchez-Matamoros, G.; Callejo, M.L.; Perez-Tyteca, P.; Llinares S. (2021). Ho prospective kindergarten teachers develop their noticing skills: The instrumentation of a learning trajectory. ZDM Mathematics Education, 53, 57-72.

DOI: https://doi.org/10.1007/s11858-021-01234-5

\title{
How prospective kindergarten teachers develop their noticing skills: the instrumentation of a learning trajectory
}

\begin{abstract}
The objective of this study was to characterise prospective kindergarten teachers' development of noticing children's thinking about length and its measurement. We used the concepts of instrumental genesis and learning trajectories to identify the ways in which prospective kindergarten teachers used a learning trajectory to learn to notice children's mathematical thinking. Following a teaching experiment, we identified three ways in which prospective kindergarten teachers used the learning trajectory to notice children's mathematical thinking. Two instrumented action schemes supported these ways of using the learning trajectory: a scheme taking into account the mathematics learning progression to interpret children's answers, and a scheme for proposing instructional tasks based on the interpretation of children's mathematical thinking. Approaching the development of noticing as an appropriation process of a learning trajectory helps us to understand prospective teachers' difficulties at endowing meaning to a learning trajectory's conceptual structure. We suggest that these ways of using learning trajectory knowledge to interpret children's mathematical thinking and to make instructional decisions can be understood as an instrumentation process which reveals how noticing skills develop.
\end{abstract}

Keywords: instrumental genesis; learning trajectory; length and its measurement; noticing; prospective kindergarten teachers. 


\section{Introduction}

Many teacher education programmes focus on helping prospective teachers to develop the competence of noticing learning situations and to act accordingly. Noticing has been conceptualised in various ways from different perspectives (Jacobs et al., 2010; Mason, 2002;Sherin et al., 2011). For example, Sherin and van Es (2009) conceptualise noticing as the processes of attending to and interpreting, which in turn, rest on a selective attention to noteworthy events and knowledgebased reasoning in which teachers make connections to broader teaching and learning principles. Jacobs et al. (2010) add to these skills that of deciding instructional responses on the basis of children's understanding. Furthermore, questions about how to support the development of noticing are currently being addressed using representations of practice (videos, narratives, curriculum material and so forth) (Amador, 2020; Fernandez \& Choy, 2020) emphasising the reciprocal interaction between what is perceived and what is known by the prospective teachers. Based on this approach to the development of noticing, some researchers advance that prospective teachers need a guide to help them structure their attention (Santagata et al., 2007; Ivars et al., 2018). In the present study, we assumed that by learning about research-based frameworks of children thinking, such as the learning trajectories, prospective teachers could begin to relate their knowledge to perceive relevant events in the teaching situations and thus develop noticing (Clements \& Sarama, 2004; Lobato \& Walters, 2017). A learning trajectory synthesises students' gradual acquisition of increasingly sophisticated mathematical concepts; therefore, a learning trajectory of a mathematical topic could help prospective teachers to perceive relevant aspects in children's strategies and interpret children's mathematical thinking in order to support appropriate instructional decisions (Wilson et al., 2013; Ivars et al., 2018).

Findings from previous research indicate that learning about mathematical learning trajectories may change prospective teachers' discourse on teaching situations and children's mathematical thinking (Wilson et al., 2017; Ivars et al., 2020). These studies focus mainly on describing and explaining changes in discursive patterns as evidence of developments in the teacher's capacity to notice children's mathematical thinking. Reporting the development of noticing through changes in their discourse is possible to the extent that prospective teachers incorporate some 
aspects of a learning trajectory. However, it is still not sufficiently understood how prospective teachers use a learning trajectory to make sense of children's learning. Nor do we sufficiently grasp how teachers relate what they perceive to theoretical information about the mathematics learning. So, there are still several open issues on how prospective teachers develop noticing (Scheiner, 2020).

Some studies on the development of noticing have centred on primary education, but few studies have centred in preschool education contexts (Parks \& Wager, 2015). Some works, however, consider that prospective kindergarten teachers need to learn to identify relevant aspects in daily life that support the learning of mathematics (Gasteiger \& Benz, 2018; Gasteiger et al., 2020) and suggest that kindergarten teachers need to acquire knowledge of mathematics learning to interpret mathematical situations in order to identify ways of enhancing children's mathematical thinking (Lee, 2017).

Based on all the above, the goal of the study was to characterise how prospective kindergarten teachers learn to use a learning trajectory to notice teaching-learning situations on length and its measurement in children aged 3-6 years how a way of developing the noticing.

\section{Theoretical framework}

We use the notions of instrumental genesis and learning trajectories to characterise how prospective kindergarten teachers develop of noticing children's understanding of length magnitude and its measurement. We describe below how these theoretical constructs were used in this study.

\subsection{Noticing}

Noticing is conceptualised in this study as one's knowledge of a context, how to reason about it (knowledge-based reasoning), and how to respond. This conceptualisation of noticing is generally associated with three components: how prospective teachers collect the relevant information of a teaching situation (attending to); how they interpret the events they attend to; and how they decide how to respond based on their interpretation of the events. 
Based on the specificity of mathematical elements, as well as their relationships and properties in previous processes, Mason (2002) characterises the development of noticing as shifts of attention that involve the capacity to discern and describe relevant details for mathematics learning, and to reason about them by recognising relationships and perceiving properties. Here, what is emphasised is a way of perceiving teaching situations and how prior knowledge affects that perception.

When prospective teachers learn to notice specific aspects of children's mathematical thinking, the information provided in the hypothetical learning trajectory can guide what they notice as well as support their interpretation processes. The connections made between specific aspects in a situation and the knowledge contained in a hypothetical learning trajectory are a manifestation of reasoning about the situation. What it is important here is how prospective teachers make sense of what they notice to understand what is happening, and how they address the evidence from a practice register as particular examples of a general feature of children's mathematical thinking (labelling or coding the event). That is to say, using agreed properties to reason about a situation and to select a teaching action as a result of that reasoning.

According to this approach, the way in which prospective teachers frame a teaching situation affects how they act. Thus, the relevance of noticing is to dispose of an available action resulting from what is noticed. The purpose of noticing is to increase the range of actions available for enactment (Mason, 2020). In this case, we obtain evidence that noticing is developing when prospective teachers generate several available actions that interrelate perceived and interpreted details, the established relationships and the properties used to endow meaning to the situation. Furthermore, one can detect that there is progress in noticing when prospective teachers refine their framing of classroom events, as evidenced by changes in prospective teachers' discourse (Llinares, 2019; Wilson et al., 2017). This approach underlines the way in which prospective teachers frame a particular event as a function of their resources, orientations and goals (Scheiner, 2020). To understand this framing process, we use the notion of instrumental genesis (Verillon \& Rabardel, 1995), described next. This theoretical approach to the development of noticing seeks to describe how prospective teachers structure classroom events, and approach and explore the teaching situation based on their own experience as well as that of the teacher education programme. 


\subsection{Noticing and Instrumental genesis}

In the research field of noticing, a mathematical learning trajectory can be understood as a cultural artefact that must be converted into an instrument in order to support prospective teachers' noticing of teaching situations. Here, the development of noticing is understood as the result of prospective teachers' interactions with the information contained in a learning trajectory-a cultural artefact - to solve specific tasks. In the process, a learning trajectory may become an instrument if prospective teachers employ it to reason about a given situation and to justify their subsequent instructional decisions. The development of an instrument was coined as instrumental genesis by Verillon and Rabardel (1995). We adapted the idea of instrumental genesis to study the development of noticing based on three dualities: artefact-instrument; scheme-technique; and instrumentationinstrumentalisation (Rabardel, 2002).

\subsubsection{Artefact-instrument}

An "artefact" is an object (not necessarily a physical one) used to perform a task. In our study, the artefact is a learning trajectory understood as a "conceptual" object, produced by research in the Didactics of Mathematics (Trouche, 2020a, 2020b). For its part, an instrument is the significant relationship between the artefact and the subject who is resolving a specific task. In the case of the development of noticing, the instrument is the way in which the learning trajectory becomes used: to attend to a teaching situation's key mathematics elements; to interpret students' mathematical thinking; and to support instructional decisions. Thus, it represents the ways in which knowledge is used to resolve the tasks.

\subsubsection{Scheme-technique: the instrumented action scheme}

The scheme-technique duality describes the links between knowledge and the subject's action. A scheme is a stable way in which knowledge guides the resolution of specific tasks. To study the development of noticing, a scheme is the stable way in which the prospective teacher uses knowledge of a learning trajectory to notice teaching situations (e.g. labelling or coding aspects in different situations as instances of a general idea). Schemes are not directly observable but can be inferred from the regularities in the way prospective teachers address the mathematics elements of the situations, interpret them and justify their decisions of action. 
Schemes allow prospective teachers to adopt similar responses when resolving a task. That is, they represent ways of using knowledge of the learning trajectory to frame a teaching-learning situation.

When prospective teachers use a learning trajectory to notice a mathematical teaching situation, they build and rely on an instrumented action scheme (Trouche, 2020a, 2020b). The instrumented action scheme is a specific instrument that belongs to a given subject, and thus depends on the knowledge of the subject. The instrumented action scheme allows the prospective teacher to understand the learning trajectory's potential and its limitations (how the knowledge items and their conceptual relationships can be used). Table 1 shows how the instrumental genesis construct was adapted to study the development of noticing (the different ways in which the learning trajectory is used to notice mathematical teaching situations).

Table 1 Instrumented action scheme for noticing teaching situations

\begin{tabular}{|c|c|c|}
\hline $\begin{array}{c}\text { (Artefact) } \\
\text { Knowledge items }\end{array}$ & INSTRUMENTED ACTION SCHEME & $\begin{array}{l}\text { Noticing } \\
\text { Skills }\end{array}$ \\
\hline $\begin{array}{l}\text { The mathematical } \\
\text { elements }\end{array}$ & $\begin{array}{l}\text { The prospective teacher links evidence in the } \\
\text { situation to mathematical elements. }\end{array}$ & Attend to \\
\hline $\begin{array}{l}\text { Progression in the } \\
\text { learning of the } \\
\text { mathematical concept }\end{array}$ & $\begin{array}{l}\text { The prospective teacher interprets evidence in } \\
\text { the situation taking into account the inclusive } \\
\text { nature of understanding levels in the learning } \\
\text { progression }\end{array}$ & Interpret \\
\hline $\begin{array}{l}\text { Learning objectives } \\
\text { related to the } \\
\text { mathematical concept }\end{array}$ & $\begin{array}{l}\text { The prospective teacher formulates learning } \\
\text { goals based on the progression of children's } \\
\text { understanding }\end{array}$ & \multirow{2}{*}{$\begin{array}{l}\text { Prospective } \\
\text { teacher } \\
\text { decision- } \\
\text { making }\end{array}$} \\
\hline Sequence of tasks & $\begin{array}{l}\text { The prospective teacher proposes a sequence } \\
\text { of instructional actions regarding the learning } \\
\text { objectives based on the progression of } \\
\text { children's understanding }\end{array}$ & \\
\hline
\end{tabular}

\subsubsection{Instrumentation-instrumentalization}

The possibilities and limitations of the learning trajectory as an artefact to help noticing a situation influence the way in which prospective teachers resolve the task. How an artefact influences a subject is called instrumentation (Trouche, 2020b). For example, how the learning trajectory is presented may determine the ways in which the prospective teacher understands and uses it. On the other hand, the way in which the learning trajectory (as an artefact) is adapted to prospective teachers to help them notice teaching situations is manifest in how prospective teachers select some parts of the learning trajectory and understand its conceptual structure. That is, the prospective teacher can modify the learning progression knowledge to adjust to it 
and respond to a particular context. This relation from a subject to an artefact is called instrumentalisation (Trouche, 2020a).

We assumed that what prospective teachers attend to is influenced and directed by their knowledge. Therefore, noticing can be regarded as a mediated action in which prospective teachers adapt the learning trajectory to the task to be solved. The ways in which a learning trajectory are used to notice situations informs us about how noticing develops, since they determine what the prospective teachers select to use. From this perspective, in accordance with Trouche (2020b), we will refer to the learning trajectory as “someone’s instrument to perform a given task, at a specific stage of their development” (p.407)

\subsection{A learning trajectory for length magnitude and its measurement}

In this study, we presented prospective kindergarten teachers with a learning trajectory for length and its measurement as a conceptual artefact (cultural tool), based on empirical research (Sarama \& Clements, 2009). The learning trajectory is: (a) a learning objective; (b) a learning progression model (Table 2); and (c) a sequence of instructional tasks. The learning trajectory has a conceptual structure characterised by the inclusive nature of the learning progression levels and the characteristics of the different mathematics elements relate to magnitude and measure. The learning progression model has two parts. First, progression in the learning of length magnitude is defined by the recognition of length magnitude, conservation and transitivity. Second, the progression in the learning of length measurement is defined by the measurement unit-a single unit of measurement, iteration, accumulation-; the relationship between the number and the measurement unit; and the universality of the measurement.

Based on the instrumental genesis approach, the objective was to characterise how prospective kindergarten teachers recognise the learning trajectory's conceptual structure and how they learn to use it to notice teaching situations-children aged 3 to 6 years learning length and its measurement. Our research questions were:

- How do prospective kindergarten teachers use a learning trajectory of length magnitude and its measurement when they are learning to notice teaching situations? 
- What characteristics relating to the development of noticing can be inferred from a learning trajectory's instrumental genesis?

Table 2 Learning progression of length magnitude and length measurement. (Adaptation of Sarama \& Clements, 2009)

\begin{tabular}{|c|c|c|}
\hline Level & Knowledge items & \\
\hline 1 & $\begin{array}{l}\text { Recognise length magnitude: } \\
\text { Identify the features of length magnitude } \\
\text { Make direct comparisons by considering length intuitively }\end{array}$ & \multirow{3}{*}{$\begin{array}{l}\text { Length } \\
\text { magnitude }\end{array}$} \\
\hline 2 & $\begin{array}{l}\text { Recognise the conservation of length magnitude: } \\
\text { Make direct comparisons by displacing objects }\end{array}$ & \\
\hline 3 & $\begin{array}{l}\text { Use the transitive property to: } \\
\text { Make indirect comparisons } \\
\text { Sort objects } \\
\text { Measure lengths }\end{array}$ & \\
\hline 4 & $\begin{array}{l}\text { Identify a measurement unit: } \\
\text { Use a single unit of measurement } \\
\text { Conduct iterations of the measurement unit } \\
\text { Recognise the accumulation property }\end{array}$ & \multirow{2}{*}{$\begin{array}{l}\text { Length } \\
\text { measurement }\end{array}$} \\
\hline 5 & $\begin{array}{l}\text { Recognise the universality of the measurement unit } \\
\text { Recognise the relationship between the number and the } \\
\text { measurement unit }\end{array}$ & \\
\hline
\end{tabular}

\section{Method}

\subsection{Participants and context}

The participants were forty-seven prospective kindergarten teachers enrolled in the Kindergarten Teacher Education Programme at the University of Alicante (Spain). These prospective kindergarten teachers had completed professional internships in early childhood schools (children aged 3 to 6 years). They already knew the schools' institutional organisation (Practicum I), but they had not yet planned and conducted a lesson (Practicum II and III). After Practicum I and before Practicum II and III, prospective kindergarten teachers participated in a teaching experiment focused on the learning and teaching of length magnitude and its measurement addressing children aged 3 to 6 years (five sessions lasting 100 minutes each).

During each session, the prospective kindergarten teachers analysed recorded videos or narratives of learning-teaching situations centred on length magnitude and its measurement at kindergarten. The prospective kindergarten teachers worked in small groups and completed the tasks in which they had to analyse teaching 
situations. The whole class then discussed the different answers. The prospective kindergarten teachers were provided with information about a learning trajectory on length magnitude and length measurement adapted from Sarama and Clements (2009) (Table 2). The learning trajectory on length magnitude was introduced in the first session and the information about length measurement in the third session.

\subsection{Tasks}

Data for this study was collected from three tasks: the initial task (session 1), the intermediate task (session 3) and the final task (session 5). Each task provided the description of a learning situation of length magnitude and its measurement with kindergarten children and three questions focused on attending to mathematical elements in the situation, interpreting children's understanding and making a subsequent instructional decision based on children's understandings:

Question 1. Justify children's understanding and point out the implicit mathematical elements.

Question 2. At which level of comprehension in the Learning Trajectory would the children be? Justify your answer.

Question 3. Assuming you are the teacher of these children, formulate a learning objective and propose a task to support children's understanding of length magnitude and its measurement.

\section{Initial task (session 1)}

The initial task was based on the video "Young children learn measurement" (Van den Heuvel-Panhuizen \& Buys, 2005) (Table 3). The situation describes a group of children aged five years who are determining their height (comparing their height and using an intermediate length to compare them). The situation is described in a series of four vignettes. Resolving the activities implies using length magnitude knowledge items (Table 2). The children's answers in Vignette 1 can be considered as evidence that they recognise length as an object's characteristic, and in Vignettes 2 and 3, as evidence of conservation. In Vignette 4, children's answers provide no evidence of the transitivity property because they arrange objects according to their length with the teacher's help.

In this teaching situation, the children's answers reflect level 2 characteristics of the learning progression model for length magnitude and its measurement. Indeed, they 
recognise the conservation of length magnitude, and make direct comparisons by displacing objects (Table 2). We expected that the prospective kindergarten teachers would identify these two mathematical elements and provide teaching activities that would elicit the transitivity property.

Table 3 Description of vignettes in the initial task

\begin{tabular}{|c|c|c|c|}
\hline Vignettes & Vignette description & Learning objective & $\begin{array}{l}\text { Knowledge items in the } \\
\text { Learning Trajectory }\end{array}$ \\
\hline 1 & $\begin{array}{l}\text { The teacher shows a paper } \\
\text { strip that is longer than the } \\
\text { children's height and asks } \\
\text { them to cut the strip to their } \\
\text { exact height }\end{array}$ & $\begin{array}{l}\text { Recognise an object's } \\
\text { height }\end{array}$ & $\begin{array}{l}\text { Recognition of attributes } \\
\text { (length magnitude) }\end{array}$ \\
\hline 2 & $\begin{array}{l}\text { One child "measures" the } \\
\text { height of another child using a } \\
\text { paper strip. The action is done } \\
\text { in pairs in different positions: } \\
\text { standing, lying down on the } \\
\text { floor, etc. }\end{array}$ & $\begin{array}{l}\text { Recognise length } \\
\text { conservation }\end{array}$ & Conservation \\
\hline 3 & $\begin{array}{l}\text { The children compare their } \\
\text { heights using the paper strips. }\end{array}$ & $\begin{array}{l}\text { Recognise length } \\
\text { conservation by } \\
\text { direct comparison } \\
\text { through displacement }\end{array}$ & Conservation \\
\hline 4 & $\begin{array}{l}\text { With the teacher's help, the } \\
\text { children compare the paper } \\
\text { strips representing their } \\
\text { height, approaching one } \\
\text { another and reasoning: "it is a } \\
\text { bit bigger..." }\end{array}$ & $\begin{array}{l}\text { Use the transitive } \\
\text { property to make } \\
\text { indirect comparisons } \\
\text { and arrange objects } \\
\text { according to their } \\
\text { lengths }\end{array}$ & Transitivity \\
\hline
\end{tabular}

\section{Intermediate task (session 3)}

The intermediate task described a situation in which two teams of children used a piece of rope to measure the contour of a tree trunk in a park (adaptation from the situation “Detectives en el parque” [Detectives in the park], Alsina, 2011). The purpose of the activity in this situation was to let the children discover the meaning of length measurement. The situation is described in a series of four vignettes (Table 4). Resolving the activities implied using length measurement knowledge items (Table 2). 
Table 4 Description of vignettes in the intermediate task

\begin{tabular}{|c|c|c|c|}
\hline Vignettes & Vignette description & $\begin{array}{l}\text { Learning } \\
\text { objective }\end{array}$ & $\begin{array}{l}\text { Knowledge items in } \\
\text { the Learning } \\
\text { Trajectory }\end{array}$ \\
\hline 1 & $\begin{array}{l}\text { In the park. The teacher asks both } \\
\text { teams to choose a tree to measure the } \\
\text { contour of the trunk and explain why } \\
\text { they chose that tree. Team A } \\
\text { answered that they chose the tree } \\
\text { because its trunk was thin. Team B } \\
\text { answered that the trunk of their tree } \\
\text { was big and thick. }\end{array}$ & $\begin{array}{l}\text { Recognise } \\
\text { the } \\
\text { measurement } \\
\text { of the } \\
\text { contour of } \\
\text { the trunk as } \\
\text { an attribute } \\
\text { of the chosen } \\
\text { trees }\end{array}$ & $\begin{array}{l}\text { Recognition of the } \\
\text { attribute }\end{array}$ \\
\hline 2 & $\begin{array}{l}\text { Both teams measured the contour of } \\
\text { the chosen tree with a rope to reply } \\
\text { to the question: which one is thicker? } \\
\text { Team A placed the rope around the } \\
\text { tree and a piece of rope was left. } \\
\text { For team B, the piece of rope was } \\
\text { not long enough to go around, which } \\
\text { is why they justified that the tree } \\
\text { they chose was thicker than the tree } \\
\text { chosen by team A. }\end{array}$ & $\begin{array}{l}\text { Identify the } \\
\text { measurement } \\
\text { unit }\end{array}$ & A measurement unit \\
\hline 3 & $\begin{array}{l}\text { The teacher insisted and asked "how } \\
\text { much". Both teams then wrapped } \\
\text { their arms around the trees: one girl } \\
\text { wrapped her arms in team A and } 4 \\
\text { members of team B wrapped their } \\
\text { arms around the tree. } \\
\text { Team B replied that the contour of } \\
\text { their tree was } 3 \text { children thicker. }\end{array}$ & $\begin{array}{l}\text { Iterate the } \\
\text { measurement } \\
\text { unit and } \\
\text { recognise the } \\
\text { accumulation }\end{array}$ & $\begin{array}{l}\text { Measurement unit: } \\
\text { Single unit of } \\
\text { measurement } \\
\text { (anthropomorphic } \\
\text { measurement unit: } \\
\text { the arms). } \\
\text { Iteration of the } \\
\text { measurement unit } \\
\text { Accumulation }\end{array}$ \\
\hline 4 & $\begin{array}{l}\text { The teacher asked: "If we change } 2 \\
\text { children for } 2 \text { other children, what } \\
\text { would the contour of the trees } \\
\text { measure?" } \\
\text { Team A answered " } 4 \text { children" } \\
\text { Team B said: "it depends on whether } \\
\text { Carmela and Luis are included or not } \\
\text { because they are smaller, in that case } \\
\text { we would need more children, but if } \\
\text { we put Sandra and Carlos, who are } \\
\text { bigger, then we would need less } \\
\text { children" }\end{array}$ & $\begin{array}{l}\text { Recognise } \\
\text { the } \\
\text { relationship } \\
\text { between } \\
\text { number and } \\
\text { measurement } \\
\text { unit }\end{array}$ & $\begin{array}{l}\text { Relationship } \\
\text { between the number } \\
\text { and the } \\
\text { measurement unit }\end{array}$ \\
\hline
\end{tabular}


The characteristics of children's answers in this situation are described next.

Children in both teams A and B used the measurement unit (iterations and accumulation). However, team A did not recognise a single unit of measurement, whereas team B recognised a single unit of measurement and the relationship between the number and the measurement unit (Table 5). For this reason, children in team A were in the transition between levels 3 and 4 of the learning progression model for length magnitude and its measurement, while children in team B may have been in the transition between levels 4 and 5 of the learning progression model (Table 2).

To support their learning progression (Table 2), prospective kindergarten teachers were expected to suggest activities in which children had to recognise a single measurement unit for team $\mathrm{A}$, and in which children had to understand the universality of the measurement unit for team B.

Table 5 Characteristics of children's' understanding in the intermediate task

\begin{tabular}{|c|c|c|c|}
\hline Team & Level & Characteristics & $\begin{array}{l}\text { Knowledge items in the } \\
\text { Learning Trajectory }\end{array}$ \\
\hline A & $3-4$ & $\begin{array}{l}\text { - They recognise length by measuring the } \\
\text { contour of a tree } \\
\text { - They use the rope and their arms as } \\
\text { measurement units } \\
\text { - They do not consider a single unit of } \\
\text { measurement } \\
\text { - It seems they do not recognise the } \\
\text { relationship between number of iterations } \\
\text { and the size of the measurement unit }\end{array}$ & $\begin{array}{l}\text { No single measurement } \\
\text { unit } \\
\text { No relationship between } \\
\text { the number and the } \\
\text { measurement unit }\end{array}$ \\
\hline B & $4-5$ & $\begin{array}{l}\text { - They recognise length by measuring the } \\
\text { contour of a tree } \\
\text { - They make indirect comparisons using } \\
\text { the rope } \\
\text { - They use the rope as a measurement unit } \\
\text { - They consider a single unit of } \\
\text { measurement } \\
\text { - They recognise the relationship between } \\
\text { the number of iterations and the size of } \\
\text { the measurement unit }\end{array}$ & $\begin{array}{l}\text { A measurement unit } \\
\text { (iteration, a single } \\
\text { measurement unit and } \\
\text { accumulation) } \\
\text { Relationship between the } \\
\text { number and the } \\
\text { measurement unit }\end{array}$ \\
\hline
\end{tabular}

\section{Final task}

The final task described a situation in which the teacher suggested making necklaces using strings of different lengths (named A, B and C), and different types 
of beads (macaroni and stars). This teaching situation was designed ad hoc (Figure $1)$.

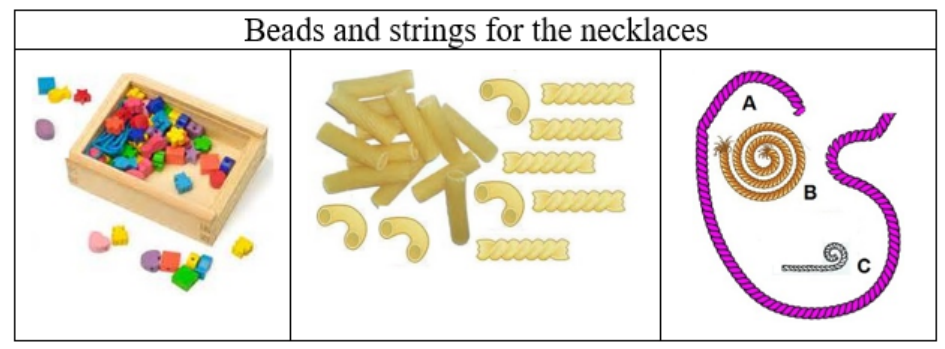

Fig. 1 Necklace beads and strings in the teaching situation described in the final task

The solutions to this activity given by four children are provided as well as their responses to the teacher's question: “who made the longest necklace?” (Table 6).

- Mario made his necklace using string $\mathrm{C}$ and 13 different types of macaroni,

- Almudena made her necklace using string A and 15 stars, ordered far apart from one another,

- Luis put 12 macaroni of the same type using string $B$, and

- Elena, using string A, put 20 stars close together.

Table 6 Descriptions of children's answers in the final task

\begin{tabular}{|c|c|c|}
\hline Situation & Learning objectives & $\begin{array}{l}\text { Knowledge items in the } \\
\text { Learning Trajectory }\end{array}$ \\
\hline $\begin{array}{l}\text { Mario considers that his } \\
\text { necklace is longer than } \\
\text { Luis's, without realising that } \\
\text { Luis's string B is longer than } \\
\text { his (string C) } \\
\text { Mario uses } 13 \text { different types } \\
\text { of macaroni. }\end{array}$ & \multirow{3}{*}{$\begin{array}{l}\text { - Recognise that the } \\
\text { necklace is as long as } \\
\text { the string. } \\
\text { - Identify that the string's } \\
\text { length does not change } \\
\text { even if it is bent or } \\
\text { stretched. } \\
\text { - Use the transitive } \\
\text { property to establish } \\
\text { which necklace is the } \\
\text { longest. } \\
\text { - Identify a measurement } \\
\text { unit (the same type of } \\
\text { bead), make iterations }\end{array}$} & $\begin{array}{l}\text { Mario: } \\
\text { No conservation. } \\
\text { A measurement unit (not a } \\
\text { single unit of measurement) }\end{array}$ \\
\hline $\begin{array}{l}\text { Almudena points out that } \\
\text { Elena's necklace is longer } \\
\text { than hers, although both are } \\
\text { made with the same string } \\
\text { (string A). } \\
\text { Almudena uses } 15 \text { stars, } \\
\text { which are far apart. }\end{array}$ & & $\begin{array}{l}\text { Almudena: } \\
\text { No conservation. } \\
\text { A measurement unit (a } \\
\text { single unit of measurement, } \\
\text { no iteration) }\end{array}$ \\
\hline $\begin{array}{l}\text { Luis considers that his } \\
\text { necklace is longer than } \\
\text { Mario's necklace because his } \\
\text { string B is longer than } \\
\text { Mario's string (C). }\end{array}$ & & $\begin{array}{l}\text { Luis: } \\
\text { Conservation. } \\
\text { A measurement unit (a } \\
\text { single unit of measurement, } \\
\text { iteration and accumulation). }\end{array}$ \\
\hline
\end{tabular}




\begin{tabular}{|l|l|l|}
\hline $\begin{array}{l}\text { Luis uses the same type of } \\
\text { macaroni close together. Luis } \\
\text { indicates the number of } \\
\text { macaroni used (12). }\end{array}$ & $\begin{array}{l}\text { and recognise the } \\
\text { accumulation. }\end{array}$ & \\
\hline $\begin{array}{l}\text { Elena uses stars that are close } \\
\text { together. }\end{array}$ & $\begin{array}{l}\text { Elena uses string A and she } \\
\text { indicates the number of stars } \\
\text { used (20). }\end{array}$ & $\begin{array}{l}\text { Elena: } \\
\text { A measurement unit a } \\
\text { single unit of measurement, } \\
\text { iteration and accumulation). }\end{array}$ \\
\hline
\end{tabular}

The characteristics of children's answers are described in Table 7 below.

Table 7 Characteristics of children's' understanding in the final task

\begin{tabular}{|c|c|c|c|}
\hline Children & Level & Characteristics & $\begin{array}{c}\text { Knowledge items } \\
\text { in the Learning } \\
\text { Trajectory }\end{array}$ \\
\hline Mario & \multirow[b]{2}{*}{1} & $\begin{array}{l}\text { - He does not understand length (magnitude) } \\
\text { conservation. } \\
\text { - He does not consider a single unit of } \\
\text { measurement. }\end{array}$ & \multirow[b]{2}{*}{ No conservation } \\
\hline Almudena & & $\begin{array}{l}\text { - She does not understand length (magnitude) } \\
\text { conservation. } \\
\text { - She considers a single unit of measurement. } \\
\text { - She does not consider the iteration of the } \\
\text { measurement unit. }\end{array}$ & \\
\hline Luis & \multirow[t]{2}{*}{4} & $\begin{array}{l}\text { - He understands the conservation of length } \\
\text { (magnitude) } \\
\text { - He identifies a measurement unit (a single } \\
\text { unit of measurement, iteration and } \\
\text { accumulation) }\end{array}$ & \multirow{2}{*}{$\begin{array}{l}\text { Conservation } \\
\text { A measurement } \\
\text { unit (a single } \\
\text { measurement } \\
\text { unit, iteration and } \\
\text { accumulation) }\end{array}$} \\
\hline Elena & & $\begin{array}{l}\text { - She identifies a measurement unit (a single } \\
\text { unit of measurement, iteration and } \\
\text { accumulation) }\end{array}$ & \\
\hline
\end{tabular}

Mario and Almudena do not recognise length conservation when counting the beads in their necklaces to compare the length without considering the string's shape. We can infer that Mario and Almudena are an example of level 1 in the learning progression model of length magnitude and its measurement (Table 2).

Luis and Elena identify a measurement unit (a single measurement unit, iteration and accumulation). We can infer that Luis and Elena are an example of level 4 in the learning progression model for length magnitude and its measurement (Table 2). To support Mario’s and Almudena’s learning progress, the prospective kindergarten teachers were expected to propose activities with the objective of acquiring length 
conservation. In the case of Luis and Elena, they were expected to suggest activities that help to acquire the concept of the relationship between number and measure.

\subsection{Analysis}

The data analysis was divided into two phases. In the first phase, we analysed prospective teachers' answers to the initial, intermediate and final answers. In the second, we compared each prospective teacher's answers in the three tasks. These two phases are described below.

In the first phase, we grouped the answers of the prospective teachers based on how they related the evidence from children's answers to knowledge items (mathematical elements and characteristics of learning progression). The criteria used were as follow: prospective teachers who only used length magnitude knowledge items; those who only used length measurement knowledge items; and those who used both length and measurement knowledge items. In each case, we focused on how the prospective teachers considered the inclusive nature of the learning progression model in the learning trajectory as reflecting the conceptual structure of learning trajectory.

Each group of answers could reflect an instrumented action scheme in cases where prospective teachers responded systematically when analysing the different teaching situations. Since schemes are not directly observable, we tried to infer them based on the regularities with which the prospective teachers attended to the elements in the situations, interpreted them and justified their decisions of action using knowledge items in the learning trajectory. Table 8 describes the criteria used to infer the instrumented action scheme built by prospective teachers.

Table 8 Criteria for inferring instrumented action schemes from Prospective Kindergarten Teachers (PKT)'s answers

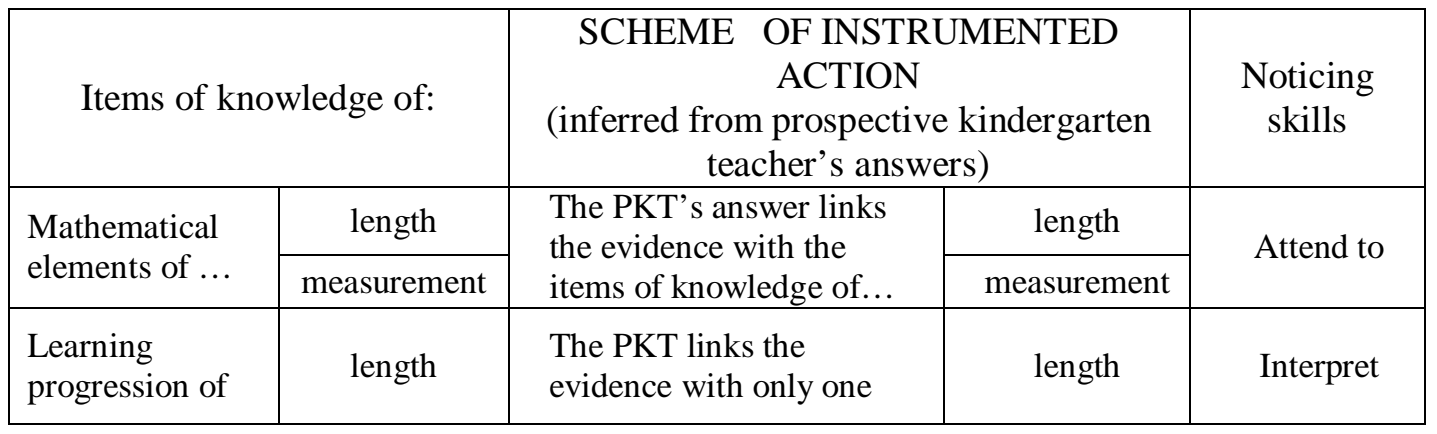




\begin{tabular}{|c|c|c|c|c|}
\hline$\cdots$ & measurement & $\begin{array}{l}\text { understanding level } \\
\text { considering the inclusive } \\
\text { nature of learning } \\
\text { progression of ... }\end{array}$ & measurement & \\
\hline \multirow{2}{*}{$\begin{array}{l}\text { Learning } \\
\text { objectives of ... }\end{array}$} & length & $\begin{array}{l}\text { The PKT proposes a } \\
\text { learning objective taking }\end{array}$ & length & \multirow{4}{*}{$\begin{array}{l}\text { Prospective } \\
\text { teacher } \\
\text { decision- } \\
\text { making }\end{array}$} \\
\hline & measurement & $\begin{array}{l}\text { progression of children's } \\
\text { understanding of ... }\end{array}$ & measurement & \\
\hline \multirow[b]{2}{*}{$\begin{array}{l}\text { Sequence of } \\
\text { activities for ... }\end{array}$} & length & \multirow{2}{*}{$\begin{array}{l}\text { The PKT proposes a } \\
\text { sequence of instructional } \\
\text { actions regarding the } \\
\text { learning objectives based } \\
\text { on the progression of } \\
\text { children's understanding } \\
\text { of ... }\end{array}$} & length & \\
\hline & measurement & & measurement & \\
\hline
\end{tabular}

In the second stage, we focused on changes in the ways the learning trajectory was used, from initial-intermediate tasks to the final task. This analytical process was carried out by a team of five researchers. First, they analysed a small sample of prospective kindergarten teachers' answers and then, they discussed the inferred characteristics. Once a consensus was reached, new data were included to verify the characteristics.

\section{Results}

We identified three ways in which the prospective kindergarten teachers used the learning trajectory to notice teaching situations of length magnitude and its measurement:

1. Using all the knowledge items in the learning trajectory to notice (attend to, interpret and instructional decision-making).

2. Partially using the learning trajectory to notice (attend to, interpret and instructional decision-making).

3. Part of the learning trajectory was used for some noticing skills.

These ways of using the learning trajectory led to determining five changes regarding the prospective kindergarten teachers' development of noticing through the teaching experiment (Figure 2).

\subsection{Using all the knowledge items from the learning trajectory to notice (attend to, interpret and instructional decision-making)}

In the final task, the prospective kindergarten teachers in this group identified all the mathematical elements in the assignments and in children's answers, linking their 
interpretations of children' understanding with evidence and using their interpretation to support their instructional decisions.

For example, Catalina, a prospective teacher in this group, linked children's answers in the final task to the knowledge items such as length recognition, conservation, iteration of the measurement unit and accumulation. Furthermore, she recognised the children' levels of understanding. For example, she justified that Mario and Almudena were at level 1 while Luis and Elena were at level 4:

Catalina: Mario is at level 1 [Table1]. He recognises length magnitude, but he doesn't compare the two strings [his and Luis's string] ... Luis is at level 4 [Table1]. He uses macaroni of the same size, iterates well, since there is nothing to suggest otherwise, and he knows that when he compares it, his string is longer than Mario's, although his necklace has 12 macaroni [Mario has 13 macaroni]. But compared to Mario, he knows that his necklace is longer because his string is bigger. Elena is at level 4 [Table1]. She chooses the longest string; she iterates the stars without leaving gaps or overlaps.

Furthermore, Catalina uses her interpretation of the children's understanding and the learning trajectory's information about instructional activities to propose activities that could support the children's progression. Catalina links each child's answers to an objective and instructional activity. She proposes a learning objective for Mario and Almudena, suggests a length-related activity, and proposes a different learning objective for Luis and Elena, suggesting a measurement activity accordingly.

Catalina: For Mario, I set the objective "Compare by displacing" [conservation] and the task is "Choose the smallest string [string C] and the largest string [string A], place them side by side and compare them”. For Elena, I set the objective "start acquiring the concept of measurement unit universality" and the task could be "which of the two necklaces is longest, Almudena's or yours? Why?”

Regarding the activities proposed for Mario and Elena, Catalina proposed different activities from those given in the learning trajectory as examples. Catalina's answers in the final task illustrate how some prospective teachers used and adapted the information from the learning trajectory to attend to, interpret and take instructional decisions. The way in which prospective teachers in this group responded can be explained by the construction of instrumented action schemes for length and its 
measurement that determine how the learning trajectory was used as an instrument (identifying the mathematical elements, relating them to learning progression levels and defining learning objectives to propose new activities). However, we identified that prospective teachers followed different routes in their instrumentation of the learning trajectory to notice teaching situations.

\subsubsection{The development trajectories of noticing when using a learning trajectory as an instrument}

The prospective kindergarten teachers in this group showed different developmental trajectories. Initially, some prospective kindergarten teachers in this group did not use the learning trajectory to notice teaching situations, while others made an unsystematic use of the knowledge items in the learning trajectory depending on the situation to analyse. These results revealed two changes that helped to characterise how noticing develops (change 4 and change 5 in Figure 2).

For example, when fulfilling the intermediate task, Catalina, the prospective teacher described above, did not provide evidence for her affirmations when reasoning about the situation. Thus, she did not link the children's responses to the measurement elements (iteration and relationship between the number and the measurement unit), nor did she identify all the knowledge items allowing to characterise the children's responses (measurement unit, uniqueness, and accumulation). Catalina only made a rhetorical use of the knowledge items provided in the learning trajectory. For example, she said:

Catalina: Team B is at level 5 because in addition to making iterations, they recognise the relationship between the number and the measurement unit.

However, other prospective kindergarten teachers in this group did initially link the children's responses to some knowledge items in the learning trajectory for length or measurement but did not use all the items that were necessary to analyse the teaching situation. This usage depended on the situation. For example, in the intermediate task, Pedro, one of the prospective teachers, only used some knowledge items on measurement to interpret team A's responses (iteration and accumulation). However, to interpret team B's responses, he used a greater number of mathematical elements (iteration, accumulation, relationship between number and measurement unit, and unity of the measurement unit). This variability in the 
level of detail of the descriptions and interpretations demonstrates that knowledge items were not systematically used. In addition, Pedro correctly interpreted the level of understanding, indicating that team A would be at a stage of transition between Levels 3 and 4, and team B at Level 5. He said:

Pedro: Vignette 3. Team A imitates team B’s iteration... Vignette 4. Team A recognises the accumulation property and performs iterations (...) Therefore, Team A would be at a stage of transition between Levels 3 and 4 [Table 1] since in the end (...), they begin to make accumulations and iterations.

Team B performs iterations and accumulation (number of children). They recognise the relationship between number and unit of measure. They recognise the non-unity of the measurement unit (see the differences between children; they are not all of the same size). They recognise the relationship between number and measurement unit. Team B is finally at Level 5 [Table 1] since they recognise that all children measure something —meaning that the children's measurement is not always the same (a single unit of measurement), [authors' explanatory note] —and so the number of necessary children [to measure the tree trunks] varies.

Furthermore, Pedro links team A's responses to an objective and an instructional activity to support the learning of the children in team A. We interpret these types of answers by considering that an instrumented action scheme linked to decisionmaking exists.

Pedro: The objective is to recognise a single unit of measurement and the task is to measure both trunks and see the differences between measurements using the rope and using their bodies.

The two changes identified shed light on the various ways in which noticing develops. One change (change 4, exemplified with Catalina), goes from not identifying mathematical elements or identifying them rhetorically (using the learning trajectory as an artefact), to interrelating the three skills with learning trajectory knowledge items. Catalina's trajectory consisted in perceiving the mathematical elements identified in each child's response with a single level of understanding, considering the inclusiveness of levels and the continuity of progression in learning; and choosing a task and linking it to the children's level of understanding considering the level sequence. The second change (change 5, 
exemplified with Pedro) represents the development from a partial instrumentation of the learning trajectory, goes from interrelating the three skills to length or measurement knowledge items - but not both - to interrelating the three skills to all knowledge items relate to length and measurement.

\subsection{Partially using the learning trajectory to notice (attend to, interpret and instructional decision-making)}

The prospective kindergarten teachers in this group completed the module partially using the knowledge items in the trajectory to analyse teaching situations. These prospective teachers identified some mathematical elements, use them to interpret some children's mathematical thinking and propose tasks so that these children continue to progress in learning. For example, Rosa, one of the prospective teachers in this group, only focused on length measurement, not on understanding of the elements of magnitude (recognising length magnitude, conservation and transitivity). Rosa linked, however, the evidence in Luis's and Elena's responses in the necklace-building activity to the mathematical elements on measurement unit: iteration and recognition of a single measurement unit. She thus interpreted the children's level of understanding using the knowledge items on measurement learning progression (Table 8).

Rosa: Elena is at level 4 because the stars she uses are joined together, that is, she avoids gaps or overlaps. So, she has acquired the concept of measurement unit iteration and Luis uses the same type of macaroni, so he has acquired the concept of single measurement unit.

Furthermore, Rosa linked Luis's and Elena's answers to an objective and to a measurement activity. She proposed an activity to Luis and Elena to support their learning of measurement based on the need to recognise a universal measurement unit.

Rosa: The task's objective is to perform measurements using anthropomorphic units and the task could be "measure the width of the classroom using your feet”.

Rosa proposed an activity in relation to Luis's and Elena's level of understanding based on the examples provided in the learning trajectory. However, Rosa did not 
focus on understanding length magnitude elements (recognising magnitude, conservation and transitivity).

We identified two prospective teachers' development trajectories that led to prospective teacher partially using the learning trajectory as an instrument to notice the teaching situations (changes 2 and 3 in Figure 2).

\subsubsection{The development trajectories of noticing leading to a partial use of the learning trajectory}

Initially, some prospective kindergarten teachers did not use the learning trajectory to notice the teaching situations (that is, the learning trajectory was an artefact) and at the end of the teaching experiment, they partially used the learning trajectory depending on the situation to be analysed (change 2, Figure 2). However, other prospective teachers initially made partial use of the learning trajectory's knowledge items depending on the situation to be analysed and linked them only to the skills attend to and interpret (Using part of the learning trajectory for some noticing skills). They finished the module using also the length or measurement knowledge items linked to decision-making (change 3, Figure 2).

One example of change 3 is Rosa. This prospective teacher in the intermediate task used only a few learning trajectory's knowledge items when attending to and interpreting the responses of teams A and B. In this way, she noticed the children's responses using measurement unit, iterations, accumulation, and relationship between the number and the measurement unit, and interpreted the children's level of understanding using the knowledge items on learning progression in measurement. However, Rosa did not propose activities to support the learning progress. In this case, Rosa proposed an activity aimed to strengthen the relationship between number and measurement unit, which does not support learning progression.

Rosa: Team A is at level 4 of comprehension, so they can identify a unit of measurement as the length of a measured object ... piece of string (Vignette 2). They recognise that when a unit is used along a length and the iterations are counted, then the "number" refers to the measurement of the trunk (Vignette 3). Team B is at level 5 of understanding, since they have acquired accumulation... four children ... (Vignette 3) that is, the longer the length of 
the measurement unit, the lesser the number of iterations (relationship between number and measure) according to the answers of the children in the team (Vignette 4).

The two changes identified reveal the various ways in which noticing develops. One change (change 2) goes from not identifying mathematical elements or identifying them rhetorically, to interrelating the three skills of magnitude or measurement, but not for both (which we can understand as a partial instrumentation of the learning trajectory). The other change, (change 3, exemplified by Rosa), goes from interrelating the skills to attend to and interpret, either for magnitude or measurement, justifying the mathematical elements using evidences; to relating the mathematical elements identified in each child's response to a level of understanding, by considering the inclusiveness of levels and the continuity of progression in learning; and to interrelating the three skills, either for length or measurement (partial instrumentation of the learning trajectory).

\subsection{Part of the learning trajectory is used for some noticing skills}

The prospective kindergarten teachers in this group ended the teaching experiment using a part of the learning trajectory for some noticing skills (attend to, interpret or instructional decision-making), but not all. For example, in the final task, Isabel, one of the prospective teachers in the group, linked Mario and Almudena's answers in the necklace-making activity with the conservation element, placing these children at level 1 in the progression:

Isabel: Mario would be at level 1, since he does not differentiate the size of the rope and takes a number of macaroni without considering their size. He says that his rope is bigger than Luis' is, because he has a larger number of macaroni, though Luis's rope is larger. Almudena is also at level 1. She focuses on the number of stars without comparing the size of the ropes.

However, Isabel did not propose objectives related to her interpretation of the children's understanding, nor instructional activities; she partially used the knowledge items to justify some of the activities to be performed. For example, Isabel proposed a measurement activity but not an activity aimed at recognising length conservation, which corresponded to her interpretation of the children's understanding. Furthermore, Isabel only used measurement knowledge items in 
relation to the instructional decision-making skill, not when identifying the mathematical elements in the situation or when interpreting children's understanding.

\subsubsection{The noticing development trajectory when a part of the learning trajectory is used for some noticing skills (but not all)}

In this group of prospective kindergarten teachers, the learning trajectory of length magnitude and its measurement initially played the role of an artefact because they did not use any knowledge items. By the end of the teaching experiment, the prospective kindergarten teachers used only some learning trajectory knowledge items to notice teaching situations (change 1, in Figure 2). They shifted from not using any learning trajectory's knowledge items to partially appropriating length or measurement knowledge items when attending to and interpreting, but not when they had to propose activities to support learning progress (use part of the learning trajectory).

\section{Discussion and conclusions}

This study aimed at characterising prospective kindergarten teachers' develop of noticing of children's mathematical thinking of length magnitude and its measurement. We used the notions of instrumental genesis and learning trajectories to identify characteristics of noticing development. After a teaching experiment, we identified three ways in which the learning trajectory was used to notice teaching situations. These three ways were based on five changes in how prospective teachers used the learning trajectory (Figure 2). The changes reveal the difficulties that prospective kindergarten teachers have in appropriating a Learning Trajectory's conceptual structure. These changes inform us about how noticing develops since they indicate how prospective kindergarten teachers learn to use a learning trajectory (as an artefact) to notice children's mathematical thinking.

We consider these changes how different development trajectories of noticing. We interpreted these differences by using an instrumental genesis approach considering how the inclusive nature of the understanding levels and the relationships between the knowledge items in the learning trajectory were used to notice teaching 
situations. This approach has the potential to contribute to the understanding of noticing development considering the use of specific information of children's learning. Indeed, it allows explaining the changes in how prospective teachers notice teaching situations, focusing our attention on the complexity of the knowledge that needs to be learnt and used by prospective teachers. By considered the development of noticing as a process by which prospective teachers appropriate the necessary knowledge through a learning trajectory (the artefact) for noticing teaching situations allows us to understand the difficulties that prospective teachers have in endowing meaning to a learning trajectory's conceptual structure. The findings of this study show how complex it is for prospective kindergarten teachers to understand and use a learning trajectory to notice teaching situations. Particularly intricate are the knowledge items, relations between the mathematics and cognition knowledge items, the inclusive nature of levels of understanding, and the relationships between attending to, interpreting and making decisions. This complexity of learning trajectory must be understood by prospective kindergarten teachers so that they can develop the noticing. Adapting instrumental genesis to study the development of noticing allows uncovering the role played by the knowledge items that must be learnt and used by prospective teachers, considering noticing as a knowledge-based reasoned process. 


\section{Final task}

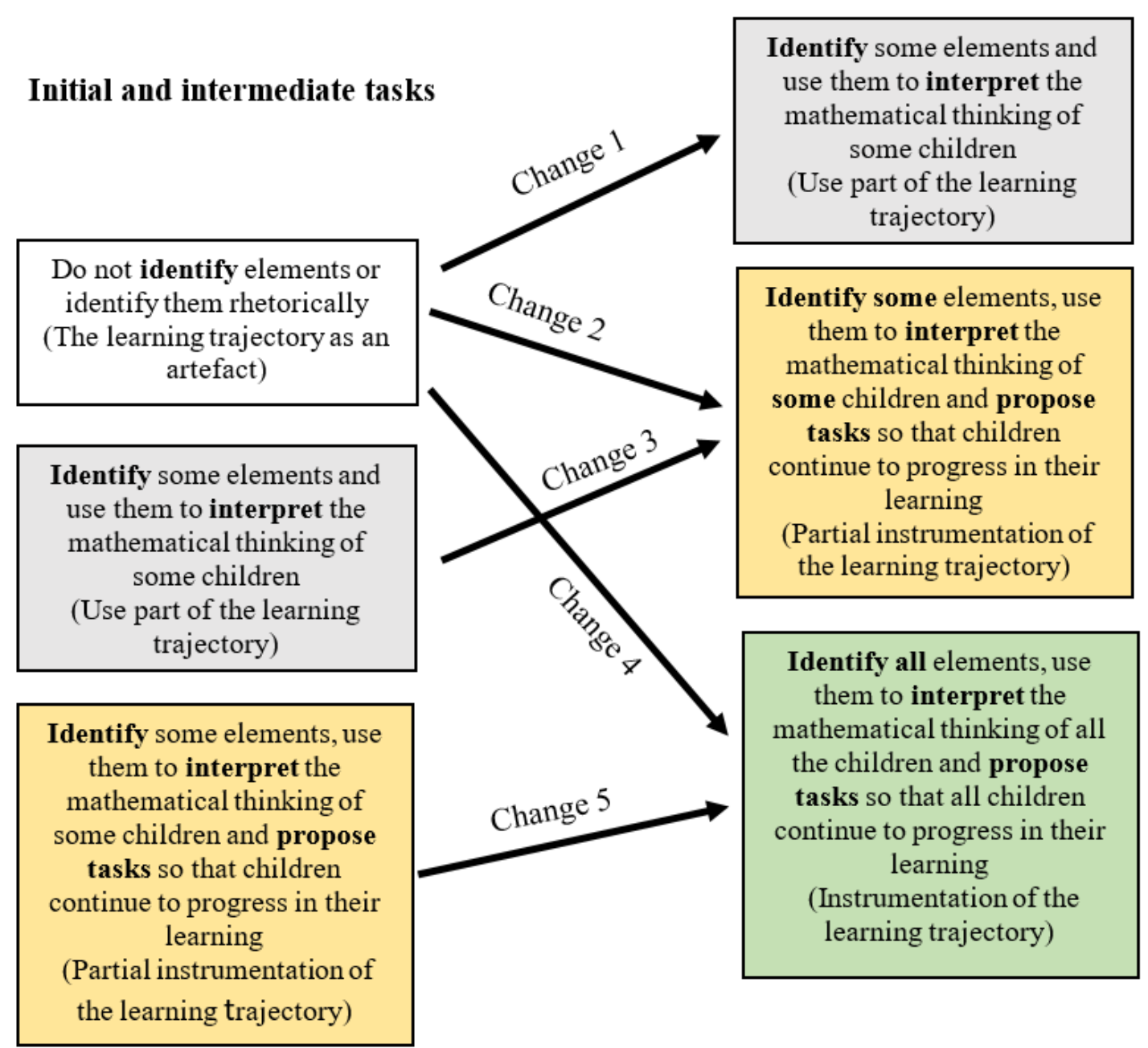

Fig. 2 Development of noticing: changes that define the transition from artefact to instrument

\subsection{The development trajectory of prospective kindergarten teachers' noticing based on instrumental genesis}

By identifying changes in how the learning trajectory was used, we were able to describe the development of prospective kindergarten teachers' noticing. Using the notion of instrumented action scheme, we were led to characterise the development trajectories of noticing in terms of two instrumented action schemes. We propose a hypothetical development trajectory based on the changes described (Figure 3).

The hypothetical development trajectory begins with the Learning Trajectory being used as an artefact. This was related to prospective kindergarten teachers' difficulties in recognising the learning situation's mathematical elements. In such cases, they presented a very general discourse and did not respond to the children's 
learning needs. The instrumentation process began when they built the instrumented action schemes, allowing them to interpret some of the children's mathematical thinking in the teaching situations but not all. The next step in their progress was the gradual recognition of the key elements and their relationships in the learning trajectory. This was revealed, for example, when they identified the mathematical elements in the activities and children's answers, as well as the inclusivity of the understanding levels. Recognising these learning trajectory features allows prospective teachers to coordinate the skills of identifying and interpreting (change 1). Furthermore, prospective teachers must take into account the sequencing of children's understanding levels, in order to generate appropriate learning objectives as well as a range of adequate instructional tasks (change 3).

The Learning Trajectory's instrumentation involves coordinating the instrumented action schemes with the noticing skills: attend to, interpret and decision-making. Instrumentation occurred when prospective kindergarten teachers identified all mathematical elements of length magnitude and its measurement involved in the teaching situation and used them in to determine children's levels of understanding, reason about them and make instructional decisions (change 5). In this noticing development trajectory, we considered the fact that the development of noticing results from the interaction between cognitive and contextual resources (Sheiner, 2016). 


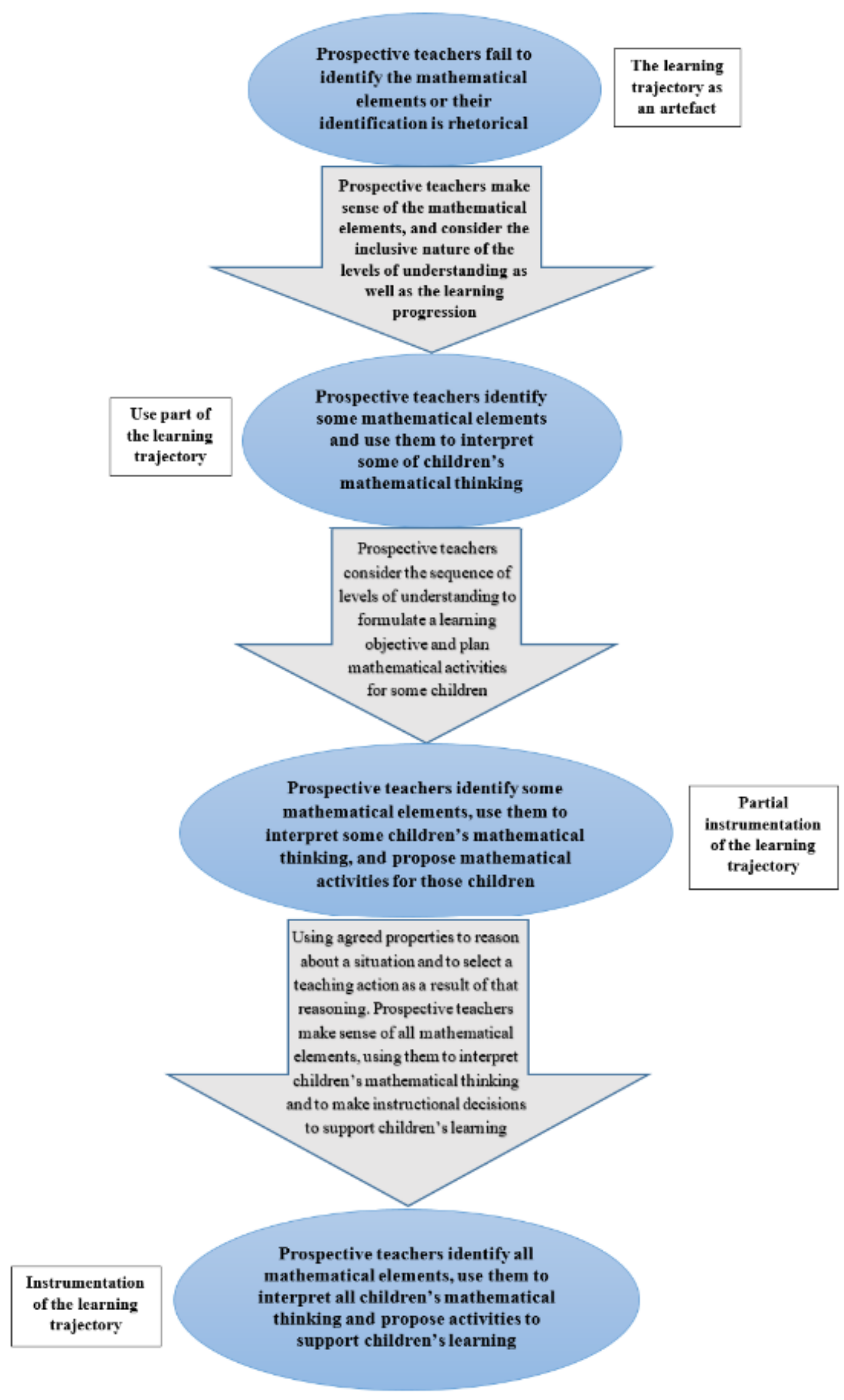

Fig. 3 Hypothetical Development Trajectory of prospective kindergarten teachers' noticing 


\subsection{Implications for the design of teacher education learning environments}

The hypothetical noticing development trajectory of prospective kindergarten teachers (Figure 3) can be used by teacher educators to design learning environments in training programmes as well as a means to assess levels of noticing development. Teacher educators can use a learning trajectory's conceptual structure as a way of organising the practice register presented to prospective kindergarten teachers. Our findings indicate that instrumental genesis, from artefact to instrument, depends on the artefact's affordances and constraints, but also on the type of tasks. Based on the above, we believe it is possible to support prospective teachers and help them to build more stable and richer schemes, which implies appropriating the Learning Trajectory and using it as a conceptual tool to notice teaching situations.

\section{Acknowledgements}

This research was funded by the national Spanish Project: EDU2017-87411-R“Ministerio de Economía and Competitividad, Gobierno de España”.

\section{References}

Alsina, A. (2011). Educación matemática en contexto: de 3 a 6 años. I.C.E. Universitat de Barcelona.

Amador, J. (2020). Noticing as a tool to analyze mathematics instruction and learning. In International Handbook of Mathematics Teacher Education. Volume 2: Tools and Processes in Mathematics Teacher Education, (pp. 310-336). Brill Sense.

Clements, D.H., \& Sarama, J. (2004). Learning trajectories in mathematics education. Mathematical Thinking and Learning, 6(2), 81-89.

Fernández, C., \& Choy, B.H. (2020). Theoretical Lenses to develop Mathematics Teacher Noticing. In International Handbook of Mathematics Teacher Education. Volume 2: Tools and Processes in Mathematics Teacher Education, (pp. 337-360). Brill Sense. 
Gasteiger, H., \& Benz, C. (2018). Enhancing and analyzing kindergarten teachers’ professional knowledge for early mathematics education. Journal of Mathematical Behavior, 51, 109-117.

https://doi.org/10.1016/j.jmathb.2018.01.002.

Gasteiger, H., Bruns, J., Benz, C., Brunner, E., \& Sprenger, P. (2020). Mathematical pedagogical content knowledge of early childhood teachers: a standardized situation-related measurement approach. ZDM Mathematics Education, 52, 193205. https://doi.org/10.1007/s11858-019-01103-2

Ivars, P., Fernández, C., Llinares, S., \& Choy, B.H. (2018). Enhancing Noticing: Using a Hypothetical Trajectory to Improve Pre-service Primary Teachers' Professional Discourse. EURASIA Journal of Mathematics, Science and Technology Education, 14(11), em1599.

Ivars, P., Fernández, C., \& Llinares, S. (2020). A Learning Trajectory as a Scaffold for Pre-service Teachers’ Noticing of Students' Mathematical Understanding. International Journal of Science and Mathematics Education, 18(3), 529-548.

Jacobs, V.R., Lamb, L.C., \& Philipp, R. A. (2010). Professional noticing of children's mathematical thinking. Journal for research in mathematics education, 41(2), 169-202.

Lee, J.E. (2017). Preschool Teachers' Pedagogical Content Knowledge in Mathematics. International Journal of Early Childhood, 49(2), 229-243. https://doi.org/10.1007/s13158-017-0189-1

Llinares, S. (2019). Indicators for the development of noticing: How do we recognize them? For the Learning of Mathematics, Monograph 1, 38-43.

Lobato, J., \& Walters, C.D. (2017). A taxonomy of approaches to learning trajectories and progressions. In J. Cai (Ed.), Compendium for Research in Mathematics Education, 74-101.

Mason, J. (2002). Researching your own practice. The discipline of noticing. Routledge.

Parks, A. M., \& Wager, A. A. (2015). What knowledge is shaping teacher preparation in early childhood mathematics? Journal of Early Childhood Teacher Education, 36(2), 124-141. DOI: https://dx.doi.org/10.1080/10901027.2015.1030520.

Rabardel, P. (2002). People and technology—a cognitive approach to contemporary instruments. Retrieved December, 15, 2011. 
Santagata, R., Zannoni, C., \& Stigler, J. W. (2007). The role of lesson analysis in pre-service teacher education: An empirical investigation of teacher learning from a virtual video-based field experience. Journal of Mathematics Teacher Education, 10(2), 123-140.

Sarama J., \& Clements D. (2009). Early Childhood Mathematics Education Research. Learning Trajectories for Young Children. Routledge.

Scheiner, T. (2016). Teacher noticing: enlightening or blinding? ZDM Mathematics Education, 48(1-2), 227-238. https://doi.org/10.1007/s11858-016-0771-2.

Scheiner, T. (2020). Towards a more comprehensive model of teacher noticing. ZDM Mathematics Education, 1-10. https://doi.org/10.1007/s11858-020-012025.

Sherin, M.G., \& van Es, E.A. (2009). Effects of video club participation on teachers’ professional vision. Journal of Teacher Education, 60(1), 20-37.

Sherin, M., Jacobs, V., \& Philipp, R. (Eds.). (2011). Mathematics teacher noticing: Seeing through teachers' eyes. Routledge.

Trouche, L. (2020a). Instrumentalization in Mathematics Education. In S. Lerman (Ed.), Encyclopedia of Mathematics Education (pp. 392-403). Springer.

Trouche, L. (2020b). Instrumentation in Mathematics Education. In S. Lerman (Ed.), Encyclopedia of Mathematics Education (pp. 404-412). Springer.

van den Heuvel-Panhuizen, M., \& Buys, K. (2005). Young children learn measurement and geometry. TAL Project. Freudenthal Institute, Utrech University and National Institute for Curriculum Development.

Verillon, P., \& Rabardel, P. (1995). Cognition and artifacts: A contribution to the study of thought in relation to instrument activity. European Journal of Psychology of Education, 9(3), 77-101.

Wilson, P.H., Mojica, G., \& Confrey, J. (2013). Learning trajectories in teacher education: Supporting teachers' understanding of students' mathematical thinking. The Journal of Mathematical Behavior, 32(2), 103-121.

Wilson, P.H., Sztajn, P., Edgington, C., Webb, J., \& Myers, M. (2017). Changes in teachers' discourse about students in a professional development on learning trajectories. American Educational Research Journal, 54(3), 568-604. 